\title{
Combined Preclinical Magnetic Particle Imaging and Magnetic Resonance Imaging: Initial Results in Mice
}

\section{Kombiniertes präklinisches Magnetic Particle Imaging und Magnetresonanztomografie: erste Ergebnisse in der Maus}

Authors

Affiliations

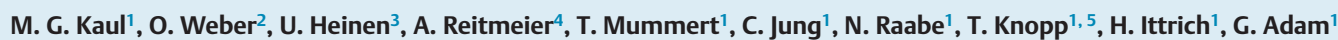

Affiliation addresses are listed at the end of the article.

Key words
magnetic particle imaging
MR imaging
superparamagnetic iron
oxide
preclinical
workflow
co-registration

received $\quad 14.11 .2014$ accepted $\quad 4.3 .2015$

\section{Bibliography}

Dol http://dx.doi.org/ 10.1055/s-0034-1399344 Published online: 2015 Fortschr Röntgenstr 2015; 187: 347-352 @ Georg Thieme Verlag KG Stuttgart · New York . ISSN 1438-9029

\section{Correspondence}

Michael Gerhard Kaul

Klinik und Poliklinik für

Diagnostische und

Interventionelle Radiologie,

Universitätsklinikum HamburgEppendorf

Martinistraße 52

20246 Hamburg

Germany

Tel.: ++ 49/40/74 10/52463

Fax: $++49 / 40 / 7410 / 53802$

mkaul@uke.uni-hamburg.de

\section{Zusammenfassung \\ $\nabla$}

Ziel: Magnetic particle imaging (MPI) ist ein neues Verfahren in der radiologischen Bildgebung und erstmalig wurde ein kommerzieller Scanner in einer präklinischen Variante installiert. Ziel der Studie war, einen Arbeitsablauf zwischen dem MPI System und einem präklinischen Magnetresonanztomografen zur vollständigen In-vivo-Untersuchung einer Maus zu etablieren und erstmalig co-registrierte In-vivo-MRMP-Bilddaten zu erzeugen.

Material und Methoden: Die Untersuchung an fünf Mäusen wurde an einem präklinischen MPI-Scanner und einem präklinischen 7-TeslaMRT-System durchgeführt. Die MRT diente zur anatomischen Referenzierung und zur Validierung der Injektion von superparamagnetischen Eisenoxidpartikeln (SPIO) während einer dynamischen MPI-Messung. Die MPI-Daten der Injektionsphase wurden extrahiert und mit MR-Bildern co-registriert.

Ergebnisse: Es konnte ein Arbeitsablauf für eine kombinierte präklinische In-vivo-MR-MPI Untersuchung etabliert werden. Eine erfolgreiche Injektion der SPIO konnte sowohl im MPI als auch im MRT nachgewiesen werden. Die MR-MPI-CoRegistrierung zeigte ein SPIO-Signal in der Vena cava inferior und dem Herzen während und nach der Injektion.

Schlussfolgerung: Daten aus einer präklinischen MPI- und MRT-Untersuchung können gemeinsam erhoben und die kombinierte MPI-MR-Bildinformation betrachtet werden.

Kernaussagen:

- Der erste kommerzielle präklinische MPI-Tomograf wurde installiert und erfolgreich in einem in vivo Experiment getestet.

- Dieses MPI-System erlaubt eine in vivo Detektion von SPIO in einem Mausmodell.

\section{Abstract \\ $\nabla$}

Purpose: Magnetic particle imaging (MPI) is a new radiologic imaging modality. For the first time, a commercial preclinical scanner is installed. The goal of this study was to establish a workflow between MPI and magnetic resonance imaging (MRI) scanners for a complete in vivo examination of a mouse and to generate the first co-registered in vivo MR-MP images.

Materials and Methods: The in vivo examination of five mice were performed on a preclinical MPI scanner and a 7 Tesla preclinical MRI system. MRI measurements were used for anatomical referencing and validation of the injection of superparamagnetic iron oxide (SPIO) particles during a dynamic MPI scan. We extracted MPI data of the injection phase and co-registered it with MRI data.

Results: A workflow process for a combined in vivo MRI and MPI examination was established. A successful injection of ferucarbotran was proven in MPI and MRI. MR-MPI co-registration allocated the SPIOs in the inferior vena cava and the heart during and shortly after the injection.

Conclusion: The acquisition of preclinical MPI and MRI data is feasible and allows the combined analysis of MR-MPI information.

Key Points:

- The first commercial preclinical MPI system was installed and has been tested successfully in an in vivo experiment.

- This MPI system can detect SPIO in vivo in a mouse model.

- First time performance of a combined in vivo MPI-MRI examination.

- Co-registered MR-MPI allows high temporal resolution imaging of the vascular SPIO distribution. 
- Erstmalige Durchführung einer kombinierten In-vivo-MRMPI-Untersuchung.

- Co-registiertes MP-MRI erlaubt eine zeitlich hochaufgelöste Abbildung der vaskulären SPIO-Biodistribution.

\section{Citation Format:}

- Kaul MG., Weber O, Heinen U et al. Combined Preclinical Magnetic Particle Imaging and Magnetic Resonance Imaging: Initial Results in a Mouse. Fortschr Röntgenstr 2015; 187: 347352

\section{Introduction}

\section{$\nabla$}

Magnetic particle imaging (MPI) is a new imaging technique. Since its initial description [1], many technical improvements and various setups of MPI scanners have been realized [2, 3]. Three years later the first in vivo MPI mouse measurement combined with a post mortem magnetic resonance imaging (MRI) examination was reported [4]. Now, with the first commercially available preclinical MPI scanner, combined preclinical MR-MPI experiments can be performed to evaluate future applications of a clinical system [5] ( $\bullet$ Fig. 1 ).

MPI is a fast imaging technique and is free of ionizing radiation. One important issue in MPI development is the indicator/tracer that has to have specific characteristics to generate an MPI signal [1]. Ferucarbotran, a superparamagnetic iron oxide (SPIO) nanoparticle [6], was developed as an MRI contrast agent for liverspecific uptake. It was shown early to be appropriate for MPI use as well [1]. While SPIOs are applied in the first place as negative contrast agents in MRI, they generate positive signals and perform as a tracer in MPI. Since MP images are background-free, they contain no anatomical information. To generate anatomical information, MRI measurements were included in the workflow. The purpose of the present study was to report the first combined use of in vivo MPI and in vivo MRI after an intravenous bo-

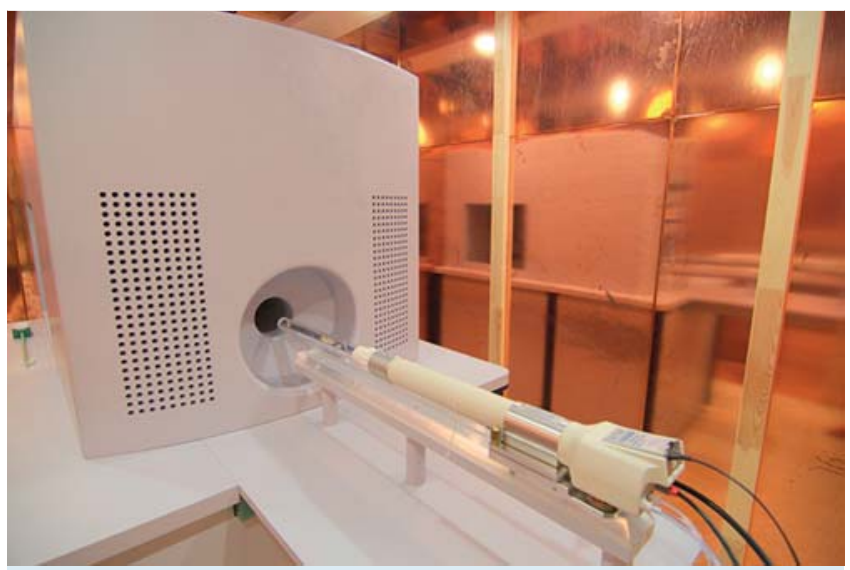

Fig. 1 Preclinical Magnetic Particle Imaging scanner is installed in a shielded cabinet. The copper coating shielding eliminates disturbances induced by external radio frequency signals. The scanner has a circular bore (diameter $\sim 12 \mathrm{~cm}$ ). With the positioning system, the animal carrier unit, which is fixed to the technical support (TSU), can be pushed into the bore. All tubes and cables for narcotics, air for the heating system, and vital sign derivation are attached to the TSU and are piped to the carrier unit.

Abb. 1 Der präklinische Magnetic Particle Imaging Scanner ist in einem abgeschirmten Raum installiert. Die Kupferbeschichtung verhindert Störungen durch externe Radiofrequenzsignale. Der Scanner besitzt eine runde Bohrung (Durchmesser $\sim 12 \mathrm{~cm}$ ). Mittels des Positionierungssystems kann die Trageeinheit, die an der technischen Unterstützungseinheit (TSU) fixiert wurde, hineingeschoben werden. An die TSU werden Schläuche für Narkosegas und Heizluft sowie eine Stromleitung für die Heizung und Lichtleiter für die Übertragung von Vitalzeichen angeschlossen und an die Trageeinheit weiter geschleust. lus injection of ferucarbotran in a mouse model and to describe the workflow, which has been established for future in vivo applications of this promising new imaging modality.

\section{Materials and Methods}

$\nabla$

\section{Animal handling}

The examination of five healthy mice was approved by the local committee on animal protection (Behörde für Gesundheit und Verbraucherschutz, Freie und Hansestadt Hamburg, Nr. 42/14). Anesthesia was carried out with 1-2\% Isoflurane (1-chloro2.2.2-trifluoroethyl difluoromethyl ether) and a flow of $0.5 \mathrm{~L} /$ min (Vapor 19.3, Dräger, Lübeck, Germany and Tec 7 Vaporizer, GE Healthcare, Chalfont St Giles, UK). A catheter (inner tube diameter $0.28 \mathrm{~mm}$, Portex, Smiths Medical International Ltd., USA) was placed in the tail vein for the ferucarbotran (Resovist ${ }^{\circledR}$, available only in Japan) injection.

\section{Workflow process}

As MPI (Philips/Bruker Preclinical MPI system) delivers no anatomical information, MRI scans were included in our workflow process (see $\bullet$ Fig. 2). For the transfer between the MRI and MPI scanners, the mouse was placed on a dedicated MPI- and MRIcompatible bench (MINERVE, Esternay, France). On the MRI and the MPI scanner this carrier was connected to a technical support unit that was attached to the scanners' positioning systems. The technical support units facilitate connectors for gas inflow and outflow, interfaces of vital signals, and for a heating system. Heated air was flowing through the hollow bench to keep the body temperature at $37^{\circ} \mathrm{C}$. Respiratory signals were processed by monitoring and gating units on the MRI (SA Instruments Inc., New York, USA) and MPI site (MINERVE, Esternay, France), respectively.

MRI scans were performed with a preclinical $7 \mathrm{~T}$ MR system (Clinscan 70/30 with syngo MR B15, Bruker Biospin GmbH, Ettlingen, Germany) before and after the MPI examination. While pre-injection MR scans at the beginning delivered anatomical images, the final scan validated the successful injection during the MPI scan and verified that no dislocation of the mouse occurred. At the MPI site a baseline scan was first performed. Images were reconstructed to validate that the mouse was MPI signal-free. Then a dynamic scan was started and after 1.5 minutes ferucarbotran was injected. Since reconstruction of a complete dynamic series is a time-consuming process, it was carried out at a later time point. Instead, we repeated the baseline scan and verified whether signal enhancement in the reconstructed images of this single $3 \mathrm{D}$ volume was visible. Finally the mouse was brought back to the MR scanner to validate the SPIO injection by detecting a signal decrease within the liver on the T2-weighted images.

MPI reconstruction was performed using the system function approach [7]. This implies that a separate calibration scan was performed beforehand using the same MPI parameters and tracer as used for the later mouse examination. Hereby, a sample tube containing pure ferucarbotran was moved by a robot through the bore of the scanner ( $\bullet$ Fig. 3). The reconstruction was processed 


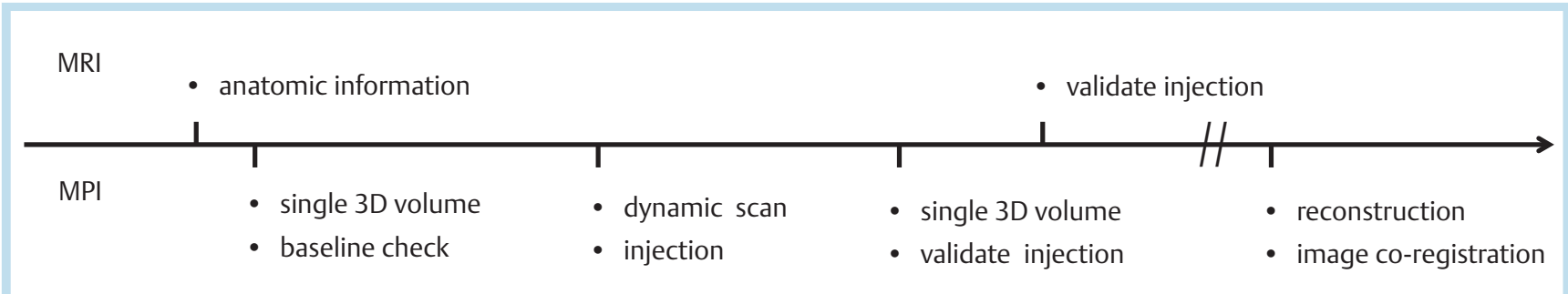

Fig. 2 A schematic timeline of the performed workflow is shown. MRI is applied before and after the MPI scan. The dynamic MPI was reconstructed at a later time point.

Abb.2 Schematische Darstellung des zeitlichen Arbeitsablaufes: MRT-Messungen wurden vor und nach der MPI-Messung durchgeführt. Die Bildrekonstruktion der dynamischen Messserie fand zu einem späteren Zeitpunkt statt.
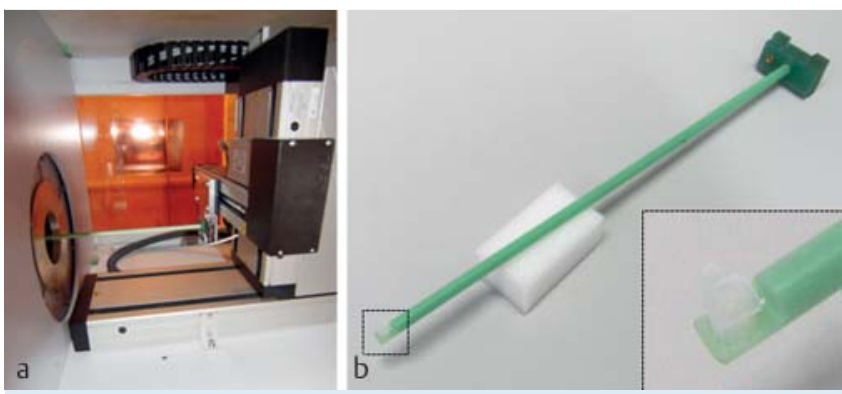

Fig. 3 A robot is used to measure system function a. It moves a calibration sample, which is mounted to the green holder $\mathbf{b}$, through the sampled volume. The size of the sample should not be larger than the voxel resolution of the reconstructed MPI images. Therefore, various sized tubes are available, in which the tracer has to be filled.

Abb.3 Zur Messung der Systemfunktion wird ein Roboter verwendet a. Er fährt eine Probe, die an einem grünen Stab befestigt ist $\mathbf{b}$, durch das Messfeld. Die Größe der Probe sollte nicht größer als die Voxelauflösung der rekonstruierten Bilder sein. Daher stehen verschieden große Probenröhrchen zur Verfügung, in die das bei der Injektion verwendete Tracer pipettiert wird.

on the MPI console (ParaVision 6.0/MPI, Bruker BioSpin MRI $\mathrm{GmbH}$ ). To visualize and extract dynamic information, additional image processing software (ImageJ, NIH, USA) extended by our own plugins (qMapIt) was used.

In the final processing step, the images were co-registered (Imalytics, Philips Medical Systems, Aachen, Germany) and the results were stored on a picture archiving system (dcm4chee 2.17, dcm4che.org). To guarantee correct co-registration of MPI and MRI data, the possibility of dislocation of the mouse during the transfer between the two scanners was minimized. Firstly, an MPI and MRI-compatible carrier unit (Equipement Vétérinaire MINERVE, Esternay, France) suitable for both systems was used to avoid rearrangements ( $\bullet$ Fig. 4). Secondly, the time of transport was short. The distance between the MPI and MRI scanner site was only 10 meters.

\section{MRI protocol}

The MRI protocol consisted of a survey scan and three respiratorytriggered T2-weighted scans which covered the chest and abdomen in a coronal, sagittal, and transverse orientation. The following scan parameters were used for the $2 \mathrm{D}$ turbo spin echo sequence: field of view (FOV) $32 \mathrm{~mm}$, matrix $256 \times 256$, slices 28 , thickness $0.8 \mathrm{~mm}$ (no gap), TR $1100 \mathrm{~ms}$ (triggered on every respira-

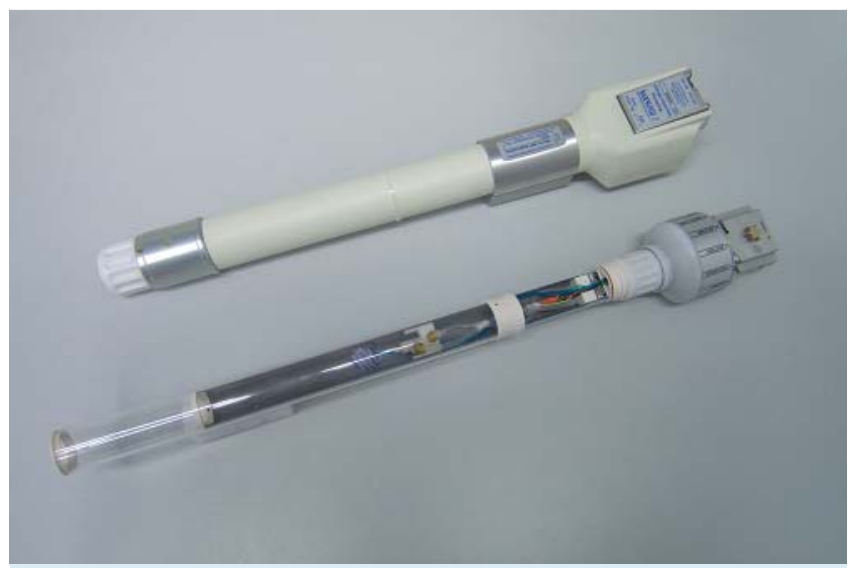

Fig. 4 Two technical support units (TSU) are shown. The upper TSU will be attached to the MPI positioning system. The lower one is used for MRI measurements. It has a mounted mouse carrier unit which can be locked by a screw. Both TSUs feature connectors and interfaces for narcotics, air for the heating system, and vital sign derivation.

Abb. 4 Dargestellt sind zwei technische Unterstützungseinheiten (TSU). Die obere TSU wird an das Positionierungssystem des MPI-Scanners befestigt, die untere wird für MRT-Messungen vorgesehen. An dieser TSU ist eine Maustrage angesteckt, welche durch eine Schraube fixiert wird. Die beiden TSUs bieten Anschlüsse und Schnittstellen für die Narkose, Luft für das Heizsystem und zur Vitalzeichenableitung.

tory cycle at 40 cycles per minute), TE $28 \mathrm{~ms}$, turbo factor 8 , NSA 3 with a scanning time of 8 minutes each. These images were used as an anatomic reference when co-registered with MP images.

\section{MPI protocol}

All MPI scans were performed with the same hardware settings. The gradient of the selection field was $1 \mathrm{~T} / \mathrm{m}$. This gradient defines the inherent resolution of the field free point (FFP). The amplitude of the drive field, which moves the FFP, was $10 \mathrm{mT}$. Together they define the sampled volume, which was a volume of $40 \times 40 \times 20 \mathrm{~mm}^{3}$ in our setting. The MPI procedure was carried out in three steps. First, a baseline control measurement was performed validating the absence of an MPI signal. The scanning time with 1000 averages was 21.5 seconds. Then a dynamic scan consisting out of 28000 repetitions without averaging was performed. It had a scanning duration of 10:03 minutes and a temporal resolution of $21.5 \mathrm{msec}$ per $3 \mathrm{D}$ volume. After the 3400 th repetition, $50 \mu \mathrm{L}$ of $500 \mathrm{mM}$ ferucarbotran were injected within 4 seconds. While the injection was performed manually in the first 
mouse, later experiments were performed with a syringe pump (AL1000 - 220Z, World Precision Instruments, Berlin, Germany) steered by the scanner's software.

\section{MPI system function, reconstruction and image co-registration}

For the system function measurement, a point sample (Bruker Biospin $\mathrm{GmbH}$, Ettlingen, Germany) filled with $7.8 \mu \mathrm{L}$ ferucarbotran covering a squared area of $2.5 \times 2.5 \mathrm{~mm}^{2}$ was used. The system matrix consisted of $20 \times 20 \times 20$ voxels covering a field of view of $60 \times 60 \times 30 \mathrm{~mm}^{3}$. It was scanned with 100 averages at each position within 9:16 hours. Using this system function, images were reconstructed using the following parameters: Kaczmarz algorithm, iterations 15 , regularization parameter $10^{-4}$, bandwidth $0.08-0.625 \mathrm{MHz}$, signal-to-noise ratio threshold 1.4 (see [8] for details of MPI reconstruction). MPI raw data can be averaged to improve signal quality. This also reduces the reconstruction time of a whole dynamic series. We reconstructed $3 \mathrm{D}$ MP images in blocks of 25 and of 100 sequentially acquired raw data sets. This resulted in a sampling time rate of 538 milliseconds and 2.15 seconds, respectively. The $3 \mathrm{D}$ volume with 100 averages of the time frame shortly after injection was then co-registered with the MR images by mutual alignment using a rigid transformation. The window settings were adjusted to highlight areas of maximal signal intensity.

\section{Results}

$\nabla$

The combined MR-MPI measurements were successfully carried out in all five mouse experiments without dislocating the mice between MRI and MPI. The comparison between pre- and post-injection MPI gave an indication that the injection was successful. This was confirmed by MRI when comparing the pre- and post-injection images, as the expected signal decrease in the liver was observed ( $\bullet$ Fig. 5 ). In the first step, the interpretation of single MP images was hindered since spatial resolution is low and anatomic references were missing. A maximum intensity projection over time frames and interpolation to a higher image matrix was used to generate an overview ( $\bullet$ Fig. 6 ). The analysis of the dynamic signal changes in depicted regions with a high MPI signal revealed distinct injection signal intensity time curves ( $\bullet$ Fig. 7). After coregistration with the high-resolution MR data, these areas could be matched with the cavities of the inferior vena cava und the heart ( $\bullet$ Fig. 8 ). Thereby, we iteratively repeated the adjustments of the rigid transformation on all three orientations. In the sagittal view, we observed a hyperintense signal region in the chest, which could be allocated in the coronal view to the heart. In the sagittal orientation the long stretched structure starting from the heart following caudal along the spine could be allocated to the inferior caval vein. The axial view through the liver (not shown) and the kidneys ( $\bullet$ Fig. 8 ) proved the signal origin as the vena cava. A coronal image through the kidney proved this as well as sagittal images.

\section{Discussion}

$\nabla$

With this study we present the first in vivo MPI images acquired during a complete in vivo MR-MPI workflow with the first commercially available preclinical MPI scanner. We repeated the workflow in five mice. Images shown in the publication are derived from the first examined mouse. The inferior vena cava was

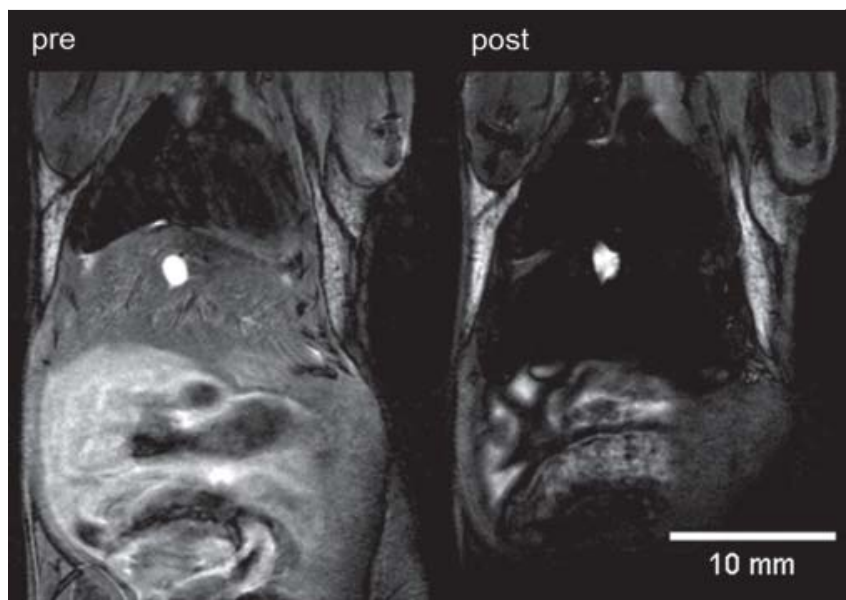

Fig. 5 Coronal T2-weighted MR images of the mouse trunk before and after an injection of the SPIO Ferucarbotran. Ferucarbotran significantly decreases the liver signal due to the uptake in liver macrophages (Kupffer cells). No displacement of the mouse between the MRI measurements could be observed.

Abb. 5 Dargestellt ist eine koronare T2-gewichtete MRT des Mausstamms vor und nach Injektion von Ferucarbotran. Ferucarbotran führt zu einer deutlichen Signalminderung in der Leber durch Aufnahme in Lebermakrophagen (Kupffer-Zellen). Es trat keine Verschiebung zwischen den MRTUntersuchungen auf.

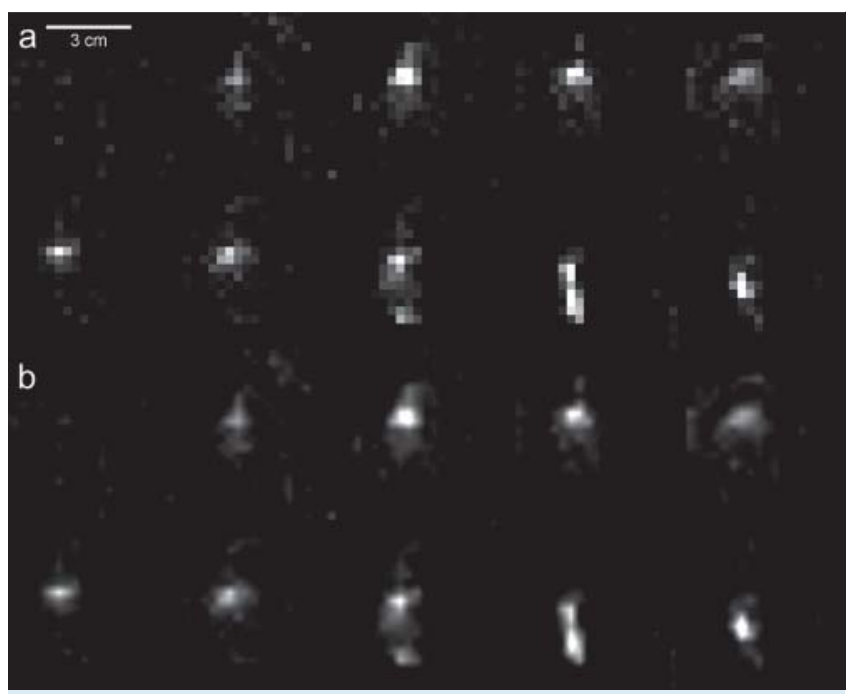

Fig. 6 MPI images of ten coronal slices $\mathbf{a}$ without and $\mathbf{b}$ with bilinear interpolation. Images were obtained after maximum intensity projection of the time series.

Abb. 6 MPI-Bilder von zehn koronaren Schichten a ohne und $\mathbf{b}$ mit bilinearer Interpolation. Die Bilder wurden mittels maximaler Intensitätsprojektion über die Zeitserie berechnet.

imaged sufficiently. This is very promising for future applications like magnetic particle angiography and MPI perfusion imaging since the scanner's diameter allows also the examination of larger animals with larger vessels. Our measurements demonstrate the need of a combined in vivo MR-MPI workflow. In our case, we performed sequential measurements using MRI before and after the MPI scan. Concepts of combined MR-MPI systems already exist and prototypes are under development [9]. A combined sys- 


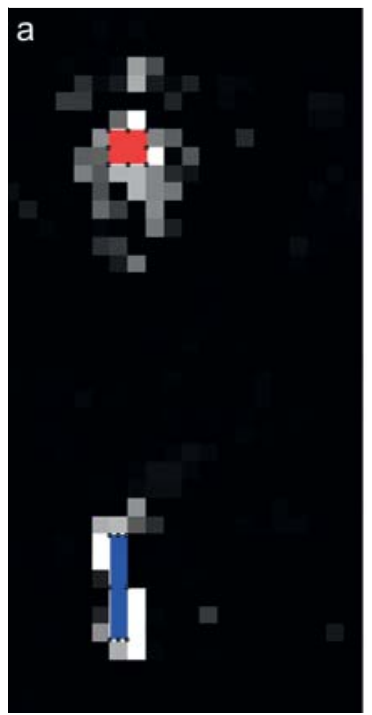

b

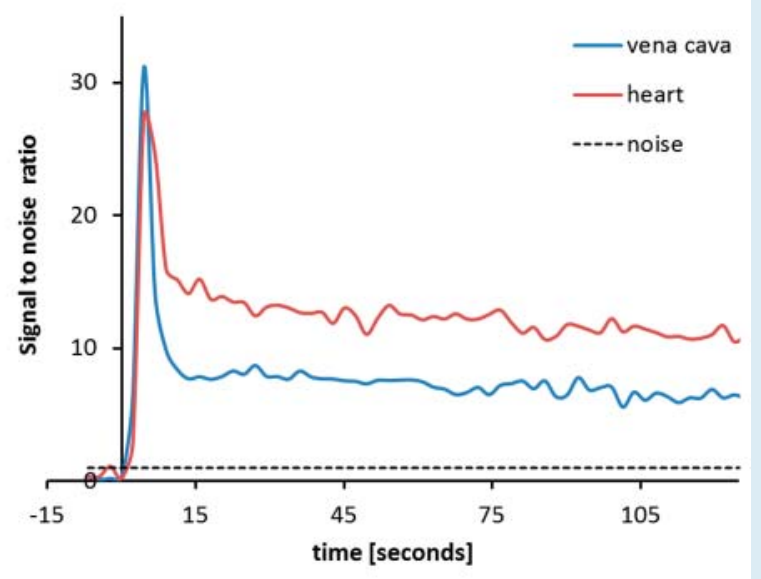

Fig. 7 Two coronal slices a out of a 3 D MPI data set at the time point of tracer injection. The image matrix is $20 \times 20$ pixels and covers an area of $6 \times 6 \mathrm{~cm}^{2}$. Two regions are marked red and blue that demonstrate $\mathbf{b}$ a significant perfusion peak immediately after injection. By co-registering with MR data, the regions could be assigned to the inferior vena cava and the heart, respectively.

Abb.7 Zwei koronar-orientierte Schichten a aus einem 3D-MPI-Datensatzes während der Tracerinjektion. Die Bildmatrix ist $20 \times 20$ Pixel groß und deckt einen Bereich von $6 \times 6 \mathrm{~cm}^{2}$ ab. Rot und blau markiert sind zwei Regionen, die $\mathbf{b}$ ein deutliches dynamisches zeitliches Verhalten wiedergeben. Gut erkennbar sind die ausgeprägten Perfusionspeaks. Mittels einer Co-Registrierung mit MRT-Datensätzen konnten die Regionen der unteren Hohlvene und dem Herzen zugeordnet werden.
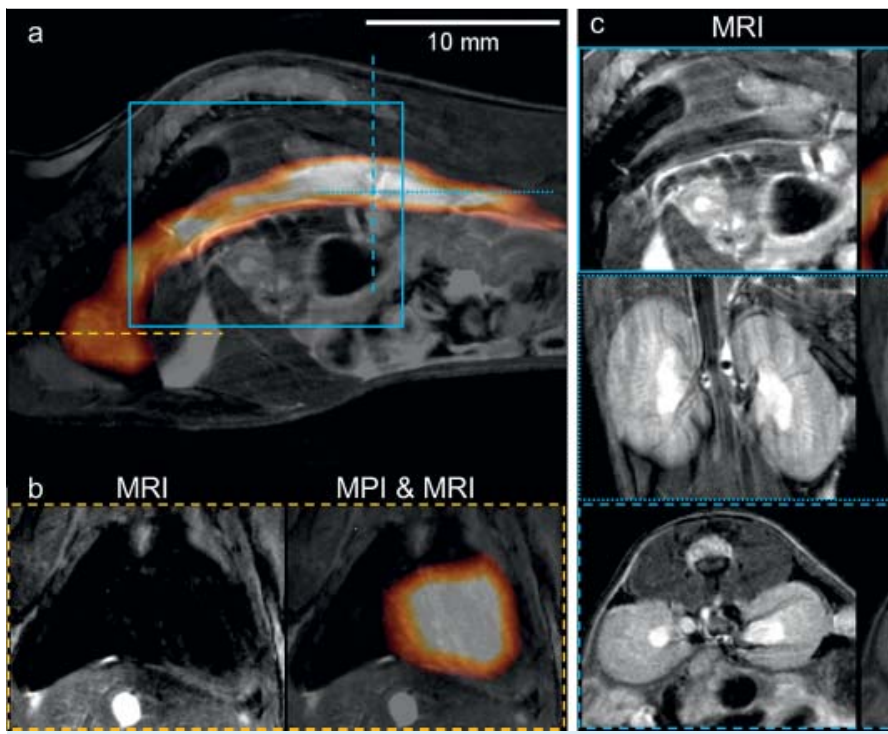

Fig. 8 While MRI is providing the anatomic information, the MPI signal shows the inflow of the tracer. a Sagittal view of co-registered MRI and MPI data. Further examined intersection planes are marked in blue and orange lines. $\mathbf{b}$ In the coronal orientation the MPI signal can be clearly allocated in the heart cavities. c The MPI signals can be allocated in the sagittal (solid blue), coronal (fine dashed blue) and transverse (dashed blue) images in accordance with the inferior vena cava.

tem would facilitate the positioning and the image co-registration process. Positioning in MPI without a reference bears the risk of missing the volume of interest. We used a drive field of $10 \mathrm{mT}$ and a gradient of $1 \mathrm{~T} / \mathrm{m}$ to cover two centimeters in the scanners' z-direction, which matched the diameter of the mouse. The FOV size scales linearly with the drive field amplitude. Furthermore, an increase in the drive field amplitude might affect the signal-to-noise ratio (SNR) positively [2].

A possible solution to avoid misplacement of the FOV would be use of fiducial markers [10]. Fiducial markers detectable in both modalities, here MPI and MRI, were not available at the time of our experiment. They might not only be used for the purpose of locating the volume of interest but also to support image co-registration. The need of an anatomic reference is comparable with PET or SPECT imaging. The images matched well after use of a rigid transformation, which takes translation and rotation into consideration. Improving resolution is an important topic when visualizing vessels. The resolution limit depends on the magnetic properties of the tracer and the selection field strength [2]. In contrast, the reconstructed voxel resolution is defined by the field of view and the sampling step size of the system function matrix. For the applied setup we achieved a voxel size of $3.0 \times 3.0 \times 1.5 \mathrm{~mm}^{3}$. Still, we were able to detect the vena cava shortly after the bolus injection, which had a diameter of only $1.2-1.6 \mathrm{~mm}$. This is very pro- 
mising for the development of a clinical scanner and its achievable resolution and underlines the potential use of MPI for angiographic purposes. The use of technically possible $2.5 \mathrm{~T} / \mathrm{m}$ instead of $1.0 \mathrm{~T} / \mathrm{m}$ would have improved resolution but would have decreased the size of the FOV. The previously reported prototype scanner had a selection field gradient strength of a maximum of $5.5 \mathrm{~T} / \mathrm{m}$ offering submillimeter resolutions $[4,11,12]$. However, it must be noted that its inner bore diameter was $32 \mathrm{~mm}$ in contrast to the diameter of $119 \mathrm{~mm}$ of our system. Larger bore sizes increase hardware requirements enormously.

As pointed out earlier, the ratio between drive field amplitude and gradient strength defines the dimensions of the FOV. To keep the FOV constant we would have to use $25 \mathrm{mT}$ at $2.5 \mathrm{~T} / \mathrm{m}$ while $12 \mathrm{mT}$ was the current preliminary scanner limit. Further improvements of the drive field strength are on the way. They will increase the flexibility of the system and its general performance. On the other hand, a large FOV and high resolution require system function that has to be more densely sampled using smaller steps of the robot and a wide range of positions. This means a drastically longer sampling time for the calibration scan and higher memory load for the computer. Possible solutions are already being discussed such as simulated system functions [13] instead of measured ones, or strategies to undersample calibration scans [14].

Sensitivity is a key aspect, but was not addressed in our study. We injected a bolus of $50 \mu \mathrm{L}$ ferucarbotran to generate an MPI signal that is 30 times the noise background when the reconstruction was performed with an averaging block size of 100 repetitions $(\bullet$ Fig. 7). When the data was reconstructed with a smaller block size of 25 repetitions, the enhancement ratio decreased and the curve became noisier. The applied volume of $50 \mu \mathrm{L}$ corresponds for instance in a $28 \mathrm{~g}$ mouse to a dose of $0.9 \mathrm{mmol} / \mathrm{kg}$ or an iron blood concentration of about $0.7 \mathrm{~g} / \mathrm{L}$. Ferucarbotran was applied in humans to detect local liver lesions. Generally, for patients above $60 \mathrm{~kg}, 1.4 \mathrm{~mL}$ of a $500 \mathrm{mM}$ solution were injected, which relates to a dose of $11.7 \mu \mathrm{mol} / \mathrm{kg}$ or an iron blood concentration of approximately $8.1 \mathrm{mg} / \mathrm{L}$. The applied MPI dose was significantly higher also in comparison to the formerly reported first in vivo MPI measurement [4]. Here the hardware specifications were optimized for mouse examinations, but our scanner is equipped with large receive coils and a larger bore diameter and can also be used for larger animals at the expense of a sensitivity loss for smaller animals. Similar to MRI, dedicated receive coils are beneficial from the SNR point of view. From our data we conclude that the dose can be reduced by a factor of three detecting a signal that is distinguishable from noise. In the near future, we will repeat the measurement to determine thresholds regarding the amount of contrast agent that is sufficient for decent image quality. Then the resolution will also be improved by combining higher drive field amplitudes and gradient strength. Further development of MPI contrast agents promises to generate stronger signals and to improve spatial resolution [15]. This is also necessary due to the fact that Resovist ${ }^{\circledR}$ is commercially available only in Japan. Finally, the process of image reconstruction has to be improved. Reconstruction is time-consuming and the quality depends on the choice of reconstruction parameters. The optimiza- tion of these parameters is performed on a subjective scale. Tools for an objective evaluation do not exist yet and have to be developed. The reconstruction process itself can be accelerated by applying compression techniques [16].

We conclude that with this first experiment a combined workflow process between a preclinical MRI system and the first commercially available preclinical MPI scanner has been demonstrated to be feasible. More work has to be done to ease the workflow process. A major drawback is the time-consuming reconstruction procedure.

\section{Affiliations \\ ' Department of Diagnostic and Interventional Radiology, University Medical Center Hamburg-Eppendorf, Hamburg, Germany \\ 2 Philips Medical Systems DMC GmbH, Hamburg, Germany \\ Bruker BioSpin MRI GmbH, Ettlingen, Germany \\ ${ }^{4}$ Animal Facility, Medical Center Hamburg-Eppendorf, Hamburg, Germany \\ 5 Hamburg University of Technology, Hamburg, Germany}

\section{References}

1 Gleich B, Weizenecker J. Tomographic imaging using the nonlinear response of magnetic particles. Nature 2005; 435: 1214-1217

2 Knopp T, Buzug TM. Magnetic Particle Imaging - An Introduction to Imaging Principles and Scanner Instrumentation; 2013, [cited 2014 Apr 1] Available from: http://www.springer.com/medicine/radiology/ book/978-3-642-04198-3

3 Saritas EU, Goodwill PW, Croft LR et al. Magnetic particle imaging (MPI) for NMR and MRI researchers. Magn Reson 2013; 229: 116-126

4 Weizenecker J, Gleich B, Rahmer J et al. Three-dimensional real-time in vivo magnetic particle imaging. Phys Med Biol 2009; 54: L1 - L10

5 Borgert J, Schmidt JD, Schmale I et al. Perspectives on clinical magnetic particle imaging. Biomed Tech (Berl) 2013; 58: 551 - 556

6 Ittrich $H$, Peldschus $K$, Raabe $N$ et al. Superparamagnetic iron oxide nanoparticles in biomedicine: applications and developments in diagnostics and therapy. Fortschr Röntgenstr 2013; 185: 1149-1166

7 Grüttner M, Knopp T, Franke J et al. On the formulation of the image reconstruction problem in magnetic particle imaging. Biomed Tech (Berl) 2013; 58: 583-591

8 Knopp T, Rahmer J, Sattel TF et al. Weighted iterative reconstruction for magnetic particle imaging. Phys Med Biol 2010; 55: 1577-1589

9 Franke J, Heinen U, Matthies L et al. IEEE. First hybrid MPI-MRI imaging system as integrated design for mice and rats: Description of the instrumentation setup. In: 2013 Int. Work. Magn. Part. Imaging. IEEE, 2013: $1-1$

10 Erickson BJ, Jack CRJ. Correlation of single photon emission CT with MR image data using fiduciary markers. AJNR Am J Neuroradiol 1993; 14: $713-720$

11 Rahmer J, Antonelli A, Sfara C et al. Nanoparticle encapsulation in red blood cells enables blood-pool magnetic particle imaging hours after injection. Phys Med Biol 2013; 58: 3965-3977

12 Gleich B, Weizenecker J, Borgert J. Experimental results on fast 2D-encoded magnetic particle imaging. Phys Med Biol 2008; 53: N81 - N84

13 Knopp T, Biederer S, Sattel TF et al. 2D model-based reconstruction for magnetic particle imaging. Med Phys 2010; 37: $485-491$

14 Knopp T, Weber A. Sparse reconstruction of the magnetic particle imaging system matrix. IEEE Trans Med Imaging 2013; 32: 1473-1480

15 Ferguson RM, Minard KR, Krishnan KM. Optimization of nanoparticle core size for magnetic particle imaging. J Magn Magn Mater 2009; 321: $1548-1551$

16 Lampe J, Bassoy C, Rahmer J et al. Fast reconstruction in magnetic particle imaging. Phys Med Biol 2012; 57: 1113-1134 